\title{
Correction to: Comparative Effectiveness of Combining MTX with Biologic Drug Therapy Versus Either MTX or Biologics Alone for Early Rheumatoid Arthritis in Adults: a Systematic Review and Network Meta-analysis
}

Katrina E. Donahue, M.D., M.P. $H^{1,2}$, Elizabeth R. Schulman, M.D. ${ }^{3}$, Gerald Gartlehner, M.D., M.P.H ${ }^{4,5}$, Beth L. Jonas, M.D., F.A.C.R.6, Emmanuel Coker-Schwimmer, M.P.H $H^{2}$, Sheila V. Patel, B.S.P.H. ${ }^{4}$, Rachel Palmieri Weber, Ph.D. ${ }^{2}$, Carla M. Bann, Ph.D. ${ }^{4}$, and Meera Viswanathan, Ph.D. ${ }^{4}$

'Department of Family Medicine, University of North Carolina, Chapel Hill, NC, USA; ${ }^{2}$ Cecil G. Sheps Center for Health Services Research, Chapel Hill, NC, USA; ${ }^{3}$ Hospital for Special Surgery, New York, NY, USA; ${ }^{4}$ RTI International, Research Triangle Park, Durham, NC, USA; ${ }^{5}$ Department for Evidence-based Medicine and Clinical Epidemiology, Danube University, Krems, Austria; 'Department of Medicine, Division of Rheumatology, Allergy, and Immunology, University of North Carolina, Chapel Hill, NC, USA.

\section{$\mathrm{J}$ Gen Intern Med}

DOI: $10.1007 / \mathrm{s} 11606-020-05839-6$

(c) Society of General Internal Medicine 2020

C ORRECTION TO: J GEN INTERN MED

https://doi.org/10.1007/s11606-019-05230-0

This article has been amended to include open access. The original article has been corrected.

The online version of the original article can be found at https://doi.org/10. 1007/s11606-019-05230-0 